\title{
Влияние адаптивной физической культуры на вегетативную регуляцию у студентов с ограниченными возможностями здоровья
}

\author{
Шумихина И.И. ${ }^{*}$, Дюжева Е.В. ${ }^{2}$, Бурт А.А. ${ }^{2}$, Сандалов И.Ю. \\ ${ }^{1}$ Удмуртский государственный университет \\ г. Ижевск, Россия \\ ORCID: oooo-0oo2-3063-4229, shuma66@mail.ru* \\ ФКУ Научно-исследовательский институт Федеральной службы исполнения наказаний \\ г. Москва, Россия \\ ORCID: oooo-ooo2-4399-299X, ele5055@yandex.ru \\ ORCID: oooo-0oo3-0118-3403, albinaburt@mail.ru \\ ORCID: oooo-Ooo2-4623-5687,igor-sandal@rambler.ru
}

\begin{abstract}
Аннотация: Каждый год увеличивается количество студентов, имеющих отклонения в состоянии здоровья, в связи с чем возрастает значение адаптивной физической культуры (АФК) - современного направления физической культуры, объектом воздействия и оздоровления в котором являются больные люди. Именно в АФК разрабатываются средства и методы, способствующие оздоровлению и адаптации лиц с отклонениями в состоянии здоровья к учебной и трудовой деятельности. Материалъ. В статье рассматривается влияние адаптивной физической культуры на регуляторные системы организма у студентов с ограниченными возможностями здоровъя. Методы исследования. Анализ и обобщение научной литературы, регистрация электрокардиограммы сердечного ритма с помощью комплекса «Варикард 2.51», анализ интервалокардиограмм с применением программы «Иским-6», ортостатическая проба, методы математической статистики. Резулътатъ. У студентов с ограниченными возможностями здоровья изучены данные вариабельности сердечного ритма до и сразу после занятий адаптивной физической культурой.Показано, что по результатам экспрессанализа вариабельности сердечного ритма с учетом индивидуального типа вегетативной регуляции можно правильно дозировать физическую нагрузку и тем самым повышать адаптивно-приспособительные возможности организма. Заключение. В работе показано, что занятия адаптивной физической культурой способствуют повышению адаптационноприспособительных возможностей организма, улучшению функционального состояния, повышению работоспособности. Важно проводить динамические исследования ВСР для оценки активности вегетативной регуляции в обеспечении работы сердечно-сосудистой системы при занятиях адаптивной физической культурой. С помощью АФК можно скорректировать вегетативный баланс у студентов с ОВЗ в покое и ортостазе. Физическая нагрузка должна строго подбираться в зависимости от патологии и исходного уровня регуляторных систем организма.

Ключевые слова: студенты, адаптивная физическая культура, вегетативная регуляция, вариабельность сердечного ритма, резервные возможности организма.
\end{abstract}

Для цитирования: Шумихина И.И.* , Дюжева Е.В., Бурт А.А., Сандалов И.Ю. Влияние адаптивной физической культуры на вегетативную регуляцию у студентов с ограниченными возможностями здоровья. Педагогико-психологические и медико-биологические проблемы физической культуры и спорта. 2020; 15(4): 95-100. DOI: 10.14526/2070-4798-2020-15-4-95-100

The influence of adaptive physical culture on vegetative regulation among disabled students

Irina I. Shumikhina ${ }^{1 *}$, Elena V. Dyuzheva ${ }^{2}$, Albina A. Burt ${ }^{2}$, Igor Yu. Sandalov ${ }^{2}$

${ }^{1}$ Udmurtiya State University

Izhevsk, Russia

ORCID: oooo-0oo2-3063-4229, shuma66@mail.ru*

${ }^{2}$ Federal Public Institutions Scientific-research Institute of Federal Service for the Execution of Sentences Moscow, Russia 
ORCID: oooo-0oo2-4399-299X, ele5055@yandex.ru

ORCID: oooo-ooo3-0118-3403, albinaburt@mail.ru

ORCID: oooo-Ooo2-4623-5687,igor-sandal@rambler.ru

\begin{abstract}
Each year the amount of disabled students increases, in this connection the importance of adaptive physical culture (APC) also increases. APC is a modern direction of physical culture, the objects of influence and improvement of which are disabled people. In APC the means and methods are created. They provide health improvement and adaptation of disabled people to educational and labor activity. Materials. The article deals with adaptive physical culture influence on regulating systems of an organism in disabled students. Research methods. Scientific sources analysis and summarizing, heart rhythm electrocardiogram registration with the help of "Varikard 2.51" complex, interval cardiogram analysis using "Iskim-6" program, orthostatic test, methods of mathematical statistics. Results. We studied the results of heart rate variability before and after adaptive physical culture lessons in disabled students. It was revealed that according to heart rate variability express-analysis, taking into consideration an individual type of vegetative regulation, it is possible to dose correctly physical load and increase adaptiveabilities of an organism. Conclusion. The work presents that adaptive physical culture lessons provide adaptive abilities of an organism, functional state and working capacity improvement. It is important to carry out dynamic study of heart rate variability (HRV) in order to estimate activity of vegetative regulation in providing cardiovascular system functioning during adaptive physical culture lessons. With the help of APC it is possible to correct vegetative balance in disabled students at rest and during orthostasis. Physical load should be chosen depending on pathology and the initial level of regulatory systems of an organism.
\end{abstract}

Keywords: students, adaptivephysicalculture, vegetative regulation, heart rate variability, reserve capacities of an organism.

For citation: Irina I. Shumikhina*, Elena V. Dyuzheva, Albina A. Burt, Igor Yu. Sandalov. The influence of adaptive physical culture on vegetative regulation among disabled students. Russian Journal of Physical Education and Sport. 2020; 15(4): 95-100. DOI: 10.14526/2070-4798-2020-15-4-95-100

\section{АКТУАЛЬНОСТЬ}

В последнее время отмечается тревожная тенденция увеличения количества студентов, освобожденных от занятий по дисциплине «Физическая культура». Справки из лечебных учреждений, предъявляемые студентами, в категоричной форме требуют освободить их от занятий физкультурой на предстоящий учебный год или на весь период обучения. Таким образом, медицинские работники рассматривают имеющиеся формы занятий по дисциплине «Физическая культура» в учебных заведениях как способные принести вред здоровью данной группе студентов. В то же время специалисты адаптивной физической культуры активно привлекают к физкультурно-спортивной деятельности даже инвалидов, способствуя тем самым максимально возможному развитию их жизнеспособности и эффективной самореализации в качестве социально значимых членов общества [3].

Передадаптивной физической культурой стоит задачареабилитации и адаптациилюдей с ограниченными возможностями к нормальной социальной среде посредствомпреодоления психологических барьеров, препятствующих ощущению полноценной жизни, а также осознания необходимости своего личного вклада в социальное развитие общества. Адаптивная физкультура рассматривается как часть общей культуры, подсистема физической культуры, одна из сфер социальной деятельности, направленная на удовлетворение потребности лиц с ограниченными возможностями в двигательной активности, восстановлении, укреплении и поддержки здоровья, личностного развития, самореализации физических и духовных сил в целях улучшения качества жизни, социализации и интеграции в общество $[7,8]$.

Цель исследования - выявить влияние занятий адаптивной физической культурой на вегетативную регуляцию у студентов с ограниченными возможностями здоровья.

МАТЕРИАЛЫ И МЕТОДЫ 
Оценка вегетативной регуляции проводилась с помощью анализа данных вариабельности сердечногоритма.Исследования вариабельности сердечного ритма проводились до и после занятия по адаптивной физической культуре. Регистрация электрокардиограммы сердечного ритма осуществлялась с помощью комплекса «Варикард 2.51» во II стандартном отведении, анализ интервалокардиограмм - с применением программы «Иским-6» [1]. Исследование проводилось в соответствии с рекомендациями рабочей группы Европейского общества кардиологии и Североамериканского общества кардиостимуляции

и

электрофизиологии [4]. Статистическая обработка данных осуществлялась с применением пакета прикладных программ Microsoft Excel 2013. Оценка показателей вариабельности сердечного ритма проведена с использованием ортостатической пробы исходное состояние в положении лежа (5 мин), затем переходный период (1 мин) и состояние в положении стоя (5 минут), общий объем затраченного времени на одно исследование вариабельности сердечного ритма составил 11 минут. В исследовании приняли участие две студентки в возрасте 20-21 год с диагнозами детский церебральный паралич, хронический гастродуоденит.

Преобладающий тип вегетативной регуляции определялся по классификации, предложенной Шлык Н.И. Согласно этой классификациивыделены четыре типа регуляции с разными диапазонами значений BCP, в основу положены показатели SI и VLF. При этом автор подчеркивает, что учет остальных временных и спектральных показателей обязателен. Кроме того, проведение ортостатического тестирования является важным, так как позволяет более детально определять уровень вегетативной реактивности и резервных возможностей организма студентов. Гипер-, гипо- и парадоксальные реакции на ортостаз указывают на снижение адаптационнорезервных возможностей в результате отклонений в состоянии здоровья $[6,9,10,11-13]$.

\section{РЕЗУЛЬТАТЫ И ОБСУЖДЕНИЕ}

Анализ вариабельности сердца студентки с диагнозом ДЦПпоказал, чтодляисходного состояния регуляторных систем характерна выраженная активность симпатической регуляции и центральных структур управления ритмом сердца. Это видно по малым значениям показателей BCP в покое (MxDMn, TP, HF, LF, VLF, ULF) и высокомустресс-индексу (SI). При визуальной оценке кардиоритмограмм, скатерграмм ВСР и ЭКГ в покое у студентки на кардиоритмограмме отсутствует вариабельность, на скатерграмме отмечается локальное скопление точек, а на ЭКГ виден жёсткий ритм сердца. Вариабельность является важным приспособительным механизмом, и отсутствие ВСР у данной студентки указывает на сниженные адаптационно-резервные возможности организма. Так, значение стрессиндекса (SI) до занятий варьирует от 98 усл.ед. и до 466 усл.ед., состояние центральных структур управления ритмом сердца находится в большом напряжении, вазомоторные волны (LF) - от 50 мс² до 1016 мс², преобладают над дыхательными волнами (HF), которые варьируют в диапазоне $68 \mathrm{Mc}^{2}-400 \mathrm{Mc}^{2}$, а волны VLF, характеризующие энергетические процессы, очень низкие - от $64 \mathrm{Mc}^{2}$ до $202 \mathrm{мc}^{2}$, что является свидетельством высокого напряжения центральной нервной системы.

На рисунке 1 представлены результаты динамического анализа ВСР в покое до и после занятия АФК, согласно которым отмечается повышение показателей BCP MxDMn, TP, HF, LF, VLF и снижение SI в покое. Эта положительная динамика в показателях ВСР в покое говорит о том, что занятия АФК способствуют коррекции регуляторных механизмов и повышению резервных возможностей организма. Однако на восьмое занятие студентка реагирует неадекватно, у нее повышается SI после занятия, a волновая структура спектра снижает свою активность, что способствует уменьшению функциональных резервов организма. Студентка отмечает, что занятию предшествовала стрессовая ситуация и она не могла расслабиться в течение всего занятия, что и повлияло на состояние регуляторных систем организма. 


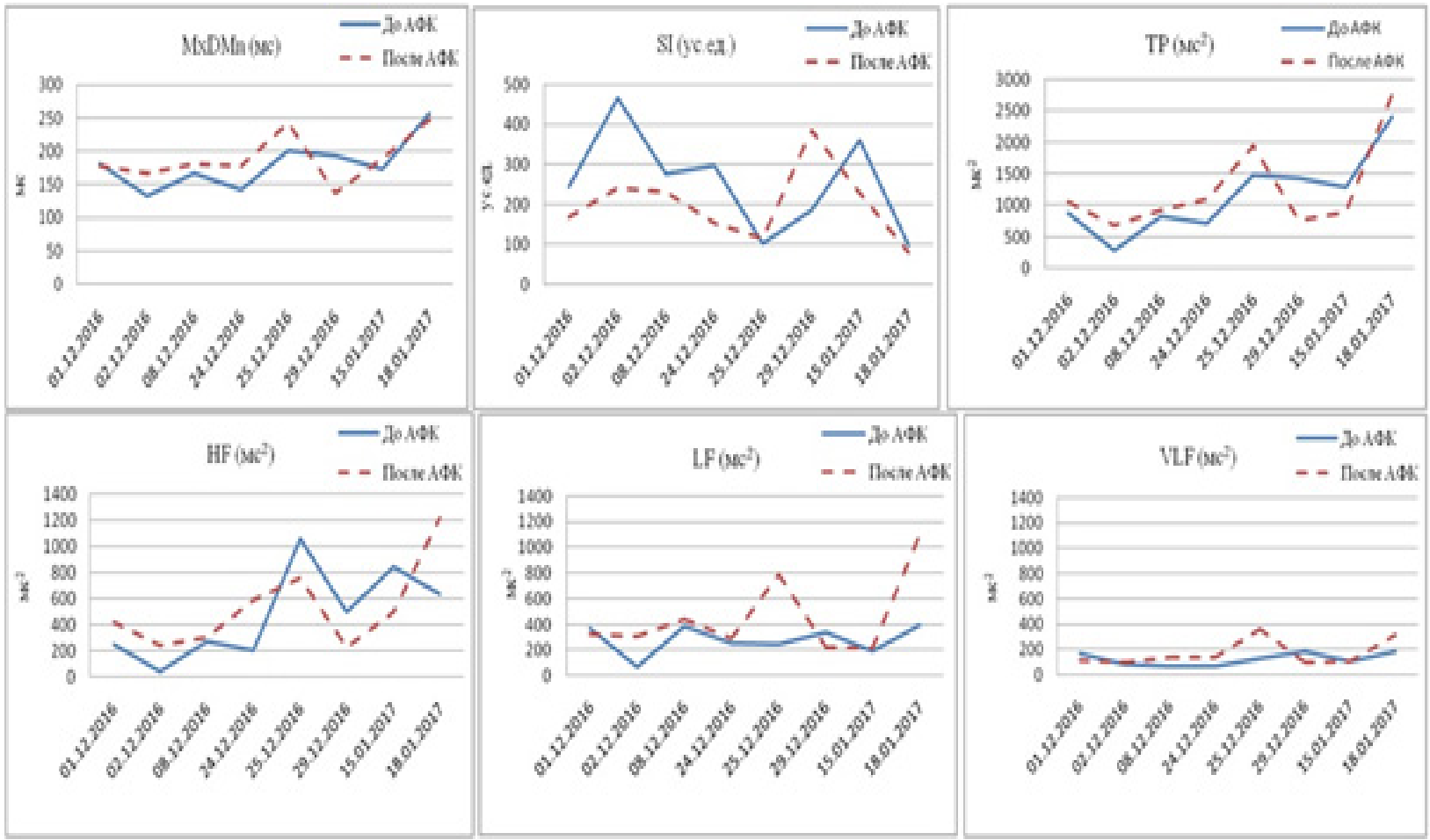

Рис. 1. Изменение показателей ВСР в покое до и после занятий АФК у студентки с ДЦП

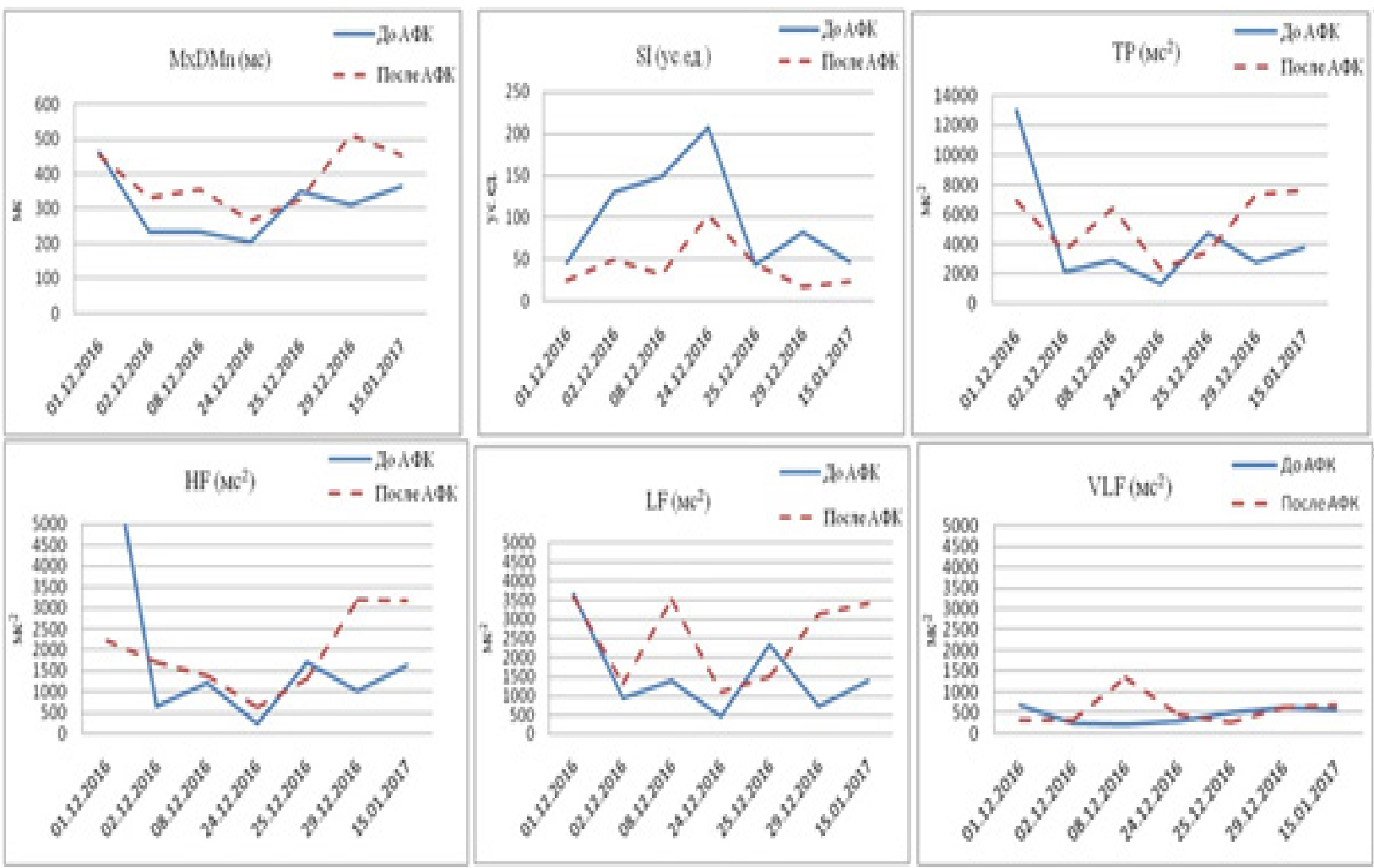

Рис. 2. Изменение показателей ВСР в покое до и после занятий АФК у студентки с хроническим гастродуоденитом 
При изучении вегетативной реактивности по результатам ортостатического тестирования выявлено, что в начале занятий у студентки отмечались парадоксальные реакции на ортостаз (когда увеличиваются показатели BCP MxDMn, TP, HF, LF вместо снижения и уменьшается SI вместо увеличения).

Такая динамика в показателях ВCP в покое и ортостазе говорит о том, что приспособительные способности у данной студентки очень низкие, затем под влиянием занятий АФК реакция нормализуется.Если перед занятиями у студентки отмечается высокое напряжение регуляторных систем организма, то в занятие включается больше дыхательных практик, упражнений на растяжение, расслабление и упражнений на мелкие мышечные группы.Сама студентка также отмечает, что у нее улучшился сон, аппетит, повысилась работоспособность.

При анализе исходных данных вариабельности ритма сердца у студентки c диагнозом хронический гастродуоденит выявлена умеренная активность автономного контура управления ритмом сердца.Для такого состояния характерны низкие значения SI и умеренно высокие показатели BCP -MxDMn, TP, HF, LF, VLF (рисунок 2).

При изучении приспособительных механизмов со стороны регуляторных систем к занятиям адаптивной физической культуройв начале занятий отмечается умеренное повышение активности симпатической регуляцииинапряжениесостороныцентральных структур управления ритмом сердца. Это видно по росту SI и снижению показателей ВCP в покое (TP, HF, LF, VLF, ULF). Такая адаптационная реакция к физической нагрузке отмечается до 4-го занятия, затем мы отмечаем снижение напряжения регуляторных систем и повышение активности парасимпатической нервной системы, которые связываем с увеличением резервных-приспособительных возможностей организма,чтоподтверждается и вегетативной реактивностью.Так, при ортостатическом тестировании до занятия отмечаются гиперреакции со стороны центральных структур управления ритмом сердца, а после занятия АФК реакция оценивается как нормальная.

Таким образом, выявлено, что после занятия АФК нормализуется функциональное состояние регуляторных систем организма и повышаются его адаптационные возможности. Необходимо отметить, что целесообразно проводить динамический контроль за уровнем вегетативного обеспечения сердечного ритма, это позволяет правильно и вовремядозировать физическую нагрузку. При неправильно подобранной физической нагрузке появляются парадоксальные реакции со стороны центральных структур управления ритмом сердца, что приводит к снижению функционального состояния организма.

\section{ЗАКЛЮЧЕНИЕ}

В работе показано, что занятия адаптивной физической культурой способствуют повышению адаптационноприспособительных возможностей организма, улучшениюфункционального состояния, повышению работоспособности. Важно проводить динамические исследования ВСР для оценки активности вегетативной регуляции в обеспечении работы сердечнососудистой системы при занятиях адаптивной физической культурой. С помощью АФК можно скорректировать вегетативный баланс у студентов с ОВЗ в покое и ортостазе. Физическая нагрузка должна строго подбираться в зависимости от патологии и исходного уровня регуляторных систем организма.

\section{СПИСОК ЛИТЕРАТУРЫ}
1.
Баевский
P.M.,
Кириллов

О.И., Клецкин С.3. Математический анализ изменений сердечного ритма при стрессе. М.: Наука. 1984: 200.

2. Гаврилова

E.A.

Ритмокардиография в спорте : монография. СПб.: Изд-во СЗГМУ им. И.И. Мечникова. 2014: 164 .

3. Иванова Е.С., Шумихина И.И. Медико-биологические основы физической культуры: учебно-методическое пособие. 
Ижевск: Изд-во УдГУ. 2018: 172.

4. Семенов Ю.Н. Использование комплексов варикард для дозирования уровней физических нагрузок в ходе спортивных тренировок. Материалы VI всероссийского симпозиума с международным участием, посвященного 85-летию образования Удмуртского государственного университета. 2016: 251-257.

5. Кончиц Н.С., Васильева T.Н. Социально-биологические аспекты оздоровительной и адаптивной физической культуры: учебное пособие. Новосибирск: Издво НИПК и ПРО. 2007: 124.

6. Лебедев Е.С., Шлык Н.И. Управление тренировочным процессом и прогнозирование спортивных результатов у биатлонисток по данным анализа вариабельности сердечного ритма. Ритм сердца и тип вегетативной регуляции в оценке уровня здоровья населения и функциональной подготовленности спортсменов: материалы VI всероссийского симпозиума. 2016: 163-166.

7. Радаев С.В., Шилько В.Г., Загревская А.И. Оздоровительная физическая культура специальной медицинской группы вуза: учебно-методическое пособие. Томск: Издво ТГУ. 2009: 61.

8. Сидоров А.С., Чепик С.В. Инновационные разделы профессионального образования учителей физической культуры, работающих с контингентом учащихся специальных медицинских групп. Учёные записки университета имени П.Ф. Лесгафта. 2011; 12(82): 150-155.

9. Шлык Н.И. Сердечный ритм и тип регуляции у детей, подростков и спортсменов: монография. Ижевск: Изд-во «Удмуртский университет». 2009: 259.

10. Кузнецов А.С., Новаковский C.В., Соломахин О.Б. О целесообразности параллельного изучения атаки и защиты в греко-римской борьбе на этапе начальной подготовки. Педагогико-психологические и медико-биологические проблемы физической культуры и спорта. 2018; 13(1): 16-26. DOI: 10/14526/01_2018_279

11. Keating X.D., Guan J., Pinero J.C., Bridges D.M. A meta-analysis of college students' physical activity behaviors. Journal of American College Health. 2005; 54: 116-126.

12. Kim S., Kim J. Mood after various brief exercise and sport modes: Aerobics, hiphop dancing, ice skating, and body conditioning. Perceptual and Motor Skills. 2007; 104: 1265-1270. DOI: 10.2466/PMS.104.3.1265-1270.

13. Ross R.M., Murthy J.N., Wollak I.D., Jackson A.S. The six minute walk test accurately estimates mean peak oxygen uptake. BMC Pulmonal Medicine. 2010; 10: 31. DOI: 10.1186/1471-2466-

\section{Статья поступила в редакцию: 20.10 .2020}

Шумихина Ирина Ивановна - кандидат биологических наук, доцент, Удмуртский государственный университет, г. Ижевск, ул. Университетская, дом 1/5, e-mail:shuта66@mail. ru

Дюжева Елена Викторовна - кандидат медицинских наук, ФКУ Научно-исследовательский институт Федеральной службы исполнения наказаний, филиал (Ижевск), 119991, г. Москва, ГСП-1, ул.Житная, дом 14, e-mail: ele5055@yandex.ru

Бурт Альбина Анасовна - кандидат медицинских наук, ФКУ Научно-исследовательский институт Федеральной службы исполнения наказаний, филиал (Ижевск), 119991, г. Москва, ГСП-1, ул. Житная, дом 14, e-mail: albinaburt@mail.ru

Сандалов Игоръ Юръевич - научный сотрудник, ФКУ Научно-исследовательский институт Федеральной службы исполнения наказаний, филиал (Ижевск), 119991, г. Москва, ГСП-1, ул. Житная, дом 14, e-mail: igor-sandal@rambler.ru 